\title{
Improving the Interprofessional Practice, Knowledge, and Skills of Health Professions Students through an Interactive Course in Gerontology
}

\author{
Elizabeth A. Mulvaney \\ Rachel Jantea \\ Paula Leslie \\ Pamela Toto \\ Mary Allias \\ Catherine Grant
}

\author{
Victoria Hornyak \\ Julie Klinger \\ Rhaven Nelson \\ Susan Skledar \\ Kylea Covaleski \\ Rollin M. Wright
}

\begin{abstract}
Interprofessional, collaborative health care is the ideal standard in geriatrics. Students' interprofessional practice skills are limited in typical siloed education. An experiential, team-based geriatrics course was designed to improve health professions (HP) students' knowledge, skills, and attitudes about interprofessional practice. Students $(n=209)$ from dentistry, medicine, nursing, nutrition, occupational therapy, pharmacy, physician assistant, social work, and speech-language pathology were assigned to interprofessional (IP) and medical-student only teams. The Interprofessional Collaborative Competency Attainment Survey-Revised (ICCAS-R) was administered preand post-course, along with program evaluations. Seventy percent of students completed both pre- and post-surveys. ICCAS-R scores were analyzed comparing the impact of training for medical students $(n=78)$ on IP teams and remaining HP students $(n=58)$. Students rated themselves as improved on all six ICCAS-R subscales (paired t-tests, $p<$ $0.05)$. Sixty-nine percent rated themselves as better able to collaborate interprofessionally. A competitive team-based learning exercise using gamification was rated as the most authentic skill-building interprofessional activity. Experiential learning where students worked with the same team helped to build interprofessional and teamwork skills. Findings will be used to improve authenticity of the clinical and teamwork content, increase the use of gamification as a teaching technique, and refine students' practice of IP teamwork competencies.
\end{abstract}

Keywords: Interprofessional education, gamification, geriatrics, competency, teamwork

Population trends in the United States show more people are living to an advanced age and that by 2035 older adults will outnumber children (Vespa et al., 2018). U.S. data suggest that $40 \%$ of hospital admissions (excluding those under age 1 year) are for people 65 years and older and that they have longer lengths of stay than other demographics (U.S.

Elizabeth A. Mulvaney, MSW, LCSW, Clinical Assistant Professor, School of Social Work, University of Pittsburgh, Pittsburgh, PA 15260. Rachel Jantea, MD, MS, Assistant Professor, Division of Geriatric \& Palliative Medicine, UTHealth McGovern Medical School, Texas School of Medicine, Houston, TX. Paula Leslie, PhD, MA (Bioethics), FRCSLT (UK), CCC-SLP (US), Senior Lecturer, Speech and Language Therapy, University of Central Lancashire, School of Sport and Health Sciences, Preston, Lancashire, UK. Pamela Toto, PhD, OTR/L, BCG, FAOTA, Associate Professor, School of Health and Rehabilitation Sciences; Mary Allias, MPAS, PA-C, DFAAPA, Assistant Professor, School of Health and Rehabilitation Sciences; Catherine Grant, DNP, FNP-BC, Assistant Professor, School of Nursing; Victoria Hornyak, DPT, GCS, Assistant Professor, School of Health and Rehabilitation Sciences; Julie Klinger, MA, Center Manager, Nationa Research and Training Center on Family Support, Health Policy Institute; Rhaven Nelson, BS, Research Programmer, University Center for Social and Urban Research; Susan Skledar, RPh, MPH, FASHP, Professor of Pharmacy \& Therapeutics, School of Pharmacy, University of Pittsburgh. Pittsburgh. Kylea Covaleski, MSW, MPH, CHES, Program Associate, Jewish Healthcare Foundation, Pittsburgh, PA. Rollin M. Wright, MD, MS, MPH, Assistant Professor, Division of Geriatric Medicine, School of Medicine, University of Pittsburgh, Pittsburgh. 
Centers for Disease Control and Prevention, 2010). As health care utilization has shifted from inpatient to outpatient settings (National Center for Health Statistics, 2017), older adults have more office-based physician visits than people at other ages (excluding infants under 1 year; Ashman et al., 2019). Moreover, one third are likely to experience a hospitalassociated disability (Covinsky et al., 2011). Meeting the needs of older patients and preventing such disability across all settings is advisable in terms of patient outcomes and health care costs.

Although professionals trained in geriatrics can assist in meeting the needs of older adults, the nation faces a shortage of specialized geriatric practitioners in most health professions, and a lack of geriatric skills and knowledge among other health practitioners (Institute of Medicine, 2008). The John A. Hartford Foundation and the Health Resources and Services Administration (HRSA) have engaged in strategies to improve workforce capacity over the last decade. The John A. Hartford Foundation invested in developing specialized scholars and practitioners in three disciplines and concluded it would not be possible to train enough specialized professionals (Isaacs/Jellinek, 2019). They pushed "that all of the nation's practicing physicians, geriatric nurses or geriatric social workers who provided care to older adults received geriatrics training in the course of their professional education" (Isaacs/Jellinek, 2019, p. 4). HRSA (n.d.) continues to make older adults' needs a focus area for its workforce development initiatives, frequently partnering with universities in this effort. Both recognize universities' role in preparing emerging professionals by assuring they have both geriatric and interprofessional education and collaborative practice (IPE/CP) knowledge and skills.

Team-based, interprofessional care surpasses care provided by individual health care professionals in both quality and safety (Baker et al., 2006; Baker et al., 2005; Barker, 2007; Cerra \& Brandt, 2015; Kohn et al., 2000). Interprofessional teamwork skills, like any other ability, need to be targeted directly in education and not left to chance in the workforce (Greiner \& Knebel, 2003; Hall \& Weaver, 2001). The Institute of Medicine's (2015) Interprofessional Learning Continuum Model suggests that IPE should begin at the undergraduate level, continue in graduate study, and be embedded in continuing professional development. According to the World Health Organization (2010), "Interprofessional education occurs when students from two or more professions learn about, from and with each other to enable effective collaboration and improve health outcomes" (p. 7). A review of IPE-related research suggests that it can promote knowledge, build skills, and positively alter attitudes about IP practice (Reeves et al., 2015). There is also a growing body of evidence that IPE might improve collaboration and patient care (Reeves et al., 2015).

In 2019, the Health Professions Accreditors Collaborative (HPAC) suggested consensus IPE terminology, definitions, and concepts compatible with existing accreditation guidelines for the 24 health professions that participated in the process. This guidance created a more uniform understanding of IPE/CP while allowing for professionspecific standards or requirements. The HPAC (2019) defined "face-to-face, synchronous learning" as "activities where students from one program learn with students from another program or with practitioners representing different professions from their own" (p. 15) and endorsed case discussions, simulations, service-learning, clinical observations, and 
clinical rotations as IPE learning modalities. The HPAC guide built on the 2011 Interprofessional Education Collaborative (IPEC) consensus statement, which was updated in 2016, to promote competency in teamwork over taskwork in order to learn interprofessional skills (IPEC, 2016; IPEC Expert Panel, 2011; Salas et al., 2008).

Characteristics of successful health care team training include multiple disciplines teaching and learning together, use of Crisis Resource Management tools, experiential team-based training or simulation exercises that reproduce realistic tasks and problemsolving scenarios, and real-time feedback to the trainee team (Chakraborti et al., 2008; Hall \& Weaver, 2001; IPEC, 2016; IPEC Expert Panel, 2011; Salas et al., 2009). Still, it is unclear which aspects or modalities of IPE are most effective in building interprofessional practice (IP) competence (Guraya \& Barr, 2018; Reeves et al., 2015). Ideally IPE programs demonstrate learner competence and impact on patient care for both students and practicing professionals continuing their development (HPAC, 2019; Institute of Medicine, 2015). To date, most studies and evaluation of university-based IPE/CP involving students are more focused on short-term change in knowledge, skills, and attitudes rather than patient outcomes (Brandt et al., 2014).

In 2008, this university's Schools of Medicine, Nursing, and Pharmacy created an introductory, experiential IPE curriculum in geriatrics to teach health professions students (HPs) about teamwork as they worked in interprofessional groups. By 2018, this effort expanded to include students and faculty from the Schools of Dental Medicine, Health and Rehabilitation Sciences, and Social Work-a collaborative representing ten professions. The course planning committee hypothesized that placing students in IP teams that completed face-to-face case discussions, simulations, and service-learning would improve their interprofessional competence as they gained knowledge and skills in geriatric practice.

\section{Method}

\section{Setting and Participants}

The course planning committee which consists of faculty representatives from each discipline (hereafter referred to as "we") developed a five-day introductory curriculum on geriatrics and interprofessional teamwork in health care for students from ten health professions representing six schools at a university in a midsize, Midwest city. The course was sponsored, coordinated by, and housed in the School of Medicine. All third-year medical students and fourth-year medical students who missed the course the previous year were required to attend. This was communicated as a curricular expectation. Graduate professional students from ten other health professions were invited to participate electively based on curricular considerations from their programs and factors such as student knowledge, student skills, curriculum sequence, clinical responsibilities, and schedule logistics. Faculty in each school and/or program recruited eligible students via email or personal communication, alerting them to the opportunity and explaining it. Students asked questions, checked with faculty from other courses, and checked with preceptors at clinical/field sites to determine feasibility of participation. Participating students included fourth year predoctoral dentistry; second-year doctor of nursing practice 
(DNPs) concentrating in family, acute, psychiatric, or nurse midwifery; second-year master's occupational therapy (OT); fourth-year pharmacy; second-year physician assistant; and first year master's speech language pathology (SLP). October 2018 represented the first year that second-year master's nutrition students and second-year or advanced standing master's social work (SW) students specializing in gerontology or integrated health care participated. Physical therapy students, who participated in years past were unable to participate during the year of this study.

\section{Curriculum Design}

Two-hundred and nine students participated in the week-long program. One-hundred and seventy-nine completed learning activities with balanced IP teams made up of 4-5 medical students and 3-4 students from the remaining health profession training programs. Based on the collective experiences in teaching IP activities, the authors rationalized that by ensuring other health profession students made up approximately half the team, we could optimize the IP experience by interrupting the concentration of power and control over the material that can occur when medical students make up the majority of the team. This resulted in 26 student teams of 8-10 people, 23 of which were interprofessional and three of which were medical student only. Each team stayed together for five team-based simulations throughout the week. Medical students attended all activities as a requirement for graduation. The experiences of the HP students, who volunteered to take the course and made it interprofessional, varied due to competing academic interests and clinical responsibilities for their respective training programs. Most HP students attended at least three days.

The original course integrated a geriatrics curriculum with some of the IPE training strategies that are currently endorsed by HPAC. Consistent with curricular quality improvement, feedback from students and faculty has continued to shape the course annually, along with evolving scholarship in geriatrics and interprofessional training. The course covered geriatrics (i.e. geriatric syndromes, preventive health and wellness, falls, mobility, functional status, pharmacology, dementia, delirium, acute care, depression, anxiety, pain, and advance care planning) and interprofessional teamwork topics (i.e. IP roles and responsibilities, communication, collaboration, and conflict management) in a variety of formats. See Table 1.

Gamification was added to increase interest and investment in learning activities, particularly for students who were required to attend rather than attending electively (Biehle \& Jeffres, 2018; Gentry et al., 2019). Gamification refers to using elements or features of games to address "real world" challenges or problems, in this case geriatric patient concerns (Biehle \& Jeffres, 2018; Gentry et al., 2019). The term often refers to using such elements in association with digitally-based learning; however, it can refer to such elements in face-to-face and simulation activities (Gentry et al., 2019), as in this course. IP teams had the opportunity to accrue points for performance on learning activities, compete head to head in activities (Is It Worth It? Activity or Hospital Survivor), use peer polling feedback through an audience response system, and earn small prizes (candy or gift cards) as well as bragging rights with their peers. 
Table 1. IPE Team Learning Activities

\begin{tabular}{|c|c|c|}
\hline $\begin{array}{l}\text { Learning } \\
\text { Activity* }\end{array}$ & Description & Modality \\
\hline $\begin{array}{l}\text { Team Building } \\
\text { Ice Breaker }\end{array}$ & $\begin{array}{l}\text { Get to know team members \& begin to work together } \\
\text { through an ice breaker (paper chain exercise) requiring } \\
\text { communication \& cooperation, introducing concepts related } \\
\text { to high-functioning teams. }\end{array}$ & $\begin{array}{l}\text { Ice breaker game in teams \& large } \\
\text { group debrief }\end{array}$ \\
\hline $\begin{array}{l}\text { Geriatric } \\
\text { Syndromes }\end{array}$ & $\begin{array}{l}\text { Review geriatric syndromes (i.e., incontinence, mobility, } \\
\text { cognitive impairment) \& their impact on care, treatment } \\
\text { outcomes, \& quality of life in older adults. Team engages in } \\
\text { problem-based, case-focused learning. }\end{array}$ & $\begin{array}{l}\text { Brief lecture with facilitated small } \\
\text { team discussion \& large group } \\
\text { debrief }\end{array}$ \\
\hline $\begin{array}{l}\text { Geriatric } \\
\text { Assessment } \\
\text { Skills Fair }\end{array}$ & $\begin{array}{l}\text { Learn to use } 12 \text { of } 18 \text { geriatric assessment tools/skills (e.g., } \\
\text { PHQ9, Mini-Cog, orthostatic hypotension, CAM) by } \\
\text { rotating to skills stations in } 15 \text {-minute intervals, receiving a } \\
\text { skill card from each for future use/reference at health fairs. } \\
\text { Skills taught by faculty \& trainees from ten professions. See } \\
\text { Table } 2 \text { for list of skill stations. }\end{array}$ & $\begin{array}{l}\text { Demonstration \& rehearsal for } \\
\text { each skill }\end{array}$ \\
\hline $\begin{array}{l}\text { Health } \\
\text { Assessment } \\
\text { Fairs }\end{array}$ & $\begin{array}{l}\text { Work in IP pairs to assess participants from senior } \\
\text { independent } \& \text { assisted living communities for geriatric } \\
\text { conditions using the tools learned at the skills fair. }\end{array}$ & $\begin{array}{l}\text { Service-learning by applying } \\
\text { recently acquired skills }\end{array}$ \\
\hline $\begin{array}{l}\text { Long-term } \\
\text { care (LTC) } \\
\text { Site Visits }\end{array}$ & $\begin{array}{l}\text { Visit \& interact with residents \& providers in three settings } \\
\text { within a LTC health care system: a dementia support unit, a } \\
\text { rehabilitation therapy room, \& an assisted living } \\
\text { community. }\end{array}$ & $\begin{array}{l}\text { Service-learning in conversation } \\
\text { with LTC residents \& clinicians }\end{array}$ \\
\hline $\begin{array}{l}\text { Advance Care } \\
\text { Planning }\end{array}$ & $\begin{array}{l}\text { Consider } \& \text { discuss own health care values } \& \text { priorities to } \\
\text { learn strategies for helping patients approach \& discuss } \\
\text { their health care values \& priorities. }\end{array}$ & Large \& small group discussion \\
\hline $\begin{array}{l}\text { Is It Worth It } \\
\text { Debate }\end{array}$ & $\begin{array}{l}\text { Argue the pro or con position on pursuing a specific course } \\
\text { of medical treatment for multiple patients considering } \\
\text { complex biopsychosocial factors, patient preferences, } \\
\text { evidence-based literature, \& ethical considerations. }\end{array}$ & $\begin{array}{l}\text { Case-based simulation of complex } \\
\text { multidisciplinary decision-making } \\
\text { about a medical intervention with a } \\
\text { discussion \& live debate between } \\
\text { IP small groups }\end{array}$ \\
\hline $\begin{array}{l}\text { Geriatric } \\
\text { Pharmacology }\end{array}$ & $\begin{array}{l}\text { Apply principles of geriatric pharmacology to a medication } \\
\text { regimen review for older patients transitioning between } \\
\text { care settings, identifying potentially harmful medications. }\end{array}$ & $\begin{array}{l}\text { Brief lecture followed by } \\
\text { multidisciplinary problem-based } \\
\text { case discussion in teams }\end{array}$ \\
\hline $\begin{array}{l}\text { Hospital } \\
\text { Survivor }\end{array}$ & $\begin{array}{l}\text { Answer questions to safely guide the course of an older } \\
\text { patient through a typical acute care hospital experience } \\
\text { wrought with risk of iatrogenic complications, prolonged } \\
\text { hospitalization, \& readmission. }\end{array}$ & $\begin{array}{l}\text { Team-based case discussion \& } \\
\text { decision-making using } \\
\text { gamification }\end{array}$ \\
\hline $\begin{array}{l}\text { Hospital } \\
\text { Horror }\end{array}$ & $\begin{array}{l}\text { Visit a simulated older adult's hospital room, identify } \\
\text { potential \& existing threats to the patient's safety, \& } \\
\text { collaborate to develop patient-centered \& systems-based } \\
\text { solutions. }\end{array}$ & $\begin{array}{l}\text { Simulation, problem-based case } \\
\text { discussion, \& large group debrief }\end{array}$ \\
\hline $\begin{array}{l}\text { Dementia } \\
\text { Positive } \\
\text { Approach to } \\
\text { Care }\end{array}$ & $\begin{array}{l}\text { Learn how brain changes in dementia lead to certain } \\
\text { behaviors \& communication mishaps. Learn how to decode } \\
\text { the meaning of these behaviors, communicate, interact with, } \\
\& \text { counsel people living with brain change. }\end{array}$ & Interactive large-group lecture \\
\hline
\end{tabular}


Table 2. Geriatric Assessment Skills Fair Stations

\begin{tabular}{|c|c|c|}
\hline Skill Station & Citations for Skill Stations & $\begin{array}{l}\text { Teaching Faculty's } \\
\text { Discipline }\end{array}$ \\
\hline $\begin{array}{l}\text { Aging in Place-Pre-clinical } \\
\text { Disability Screen }\end{array}$ & $\begin{array}{l}\text { Fried et al., 1996; Kempen et al., } \\
2008\end{array}$ & Occupational Therapy \\
\hline $\begin{array}{l}\text { Anticholinergic } \\
\text { (medication) Screening }\end{array}$ & $\begin{array}{l}\text { Collamati et al., 2016; Coupland } \\
\text { et al., } 2019\end{array}$ & Pharmacy \\
\hline $\begin{array}{l}\text { Anxiety (Generalized } \\
\text { Anxiety Disorder-7) }\end{array}$ & Spitzer et al., 2006 & Nursing \\
\hline Brief Language Assessment & & $\begin{array}{l}\text { Speech-Language } \\
\text { Pathology }\end{array}$ \\
\hline Cognition (Mini-Cog)* & $\begin{array}{l}\text { Borson et al., 2005; Mini-Cog@, } \\
\text { n.d. }\end{array}$ & $\begin{array}{l}\text { Geriatric Medicine \& } \\
\text { Physician Assistant }\end{array}$ \\
\hline $\begin{array}{l}\text { Confusion Assessment } \\
\text { Method - Delirium }\end{array}$ & Inouye et al., 1999 & Geriatric Medicine \\
\hline Deprescribing & $\begin{array}{l}\text { Felton et al., 2019; Holmes et al., } \\
\text { 2006; Kua et al., 2019; } \\
\text { Pruskowski et al., 2019; Scott, et } \\
\text { al, 2015; Thompson, et al, } 2019\end{array}$ & Pharmacy \\
\hline Depression (PHQ2)* & $\begin{array}{l}\text { Kroenke et al., 2001; Sheikh \& } \\
\text { Yesavage, 1986; Shear et al., } 2011\end{array}$ & $\begin{array}{l}\text { Internal / Geriatric } \\
\text { Medicine }\end{array}$ \\
\hline $\begin{array}{l}\text { Fall Risk (Timed Up and } \\
\text { Go) }\end{array}$ & Quach et al., 2011 & Physical Therapy \\
\hline Frailty (Frail Scale)* & $\begin{array}{l}\text { Morley et al., 2013; Rockwood et } \\
\text { al., } 2005\end{array}$ & Geriatric Medicine \\
\hline $\begin{array}{l}\text { Hearing \& Communication } \\
\text { (HHIE-S) }\end{array}$ & Ventry \& Weinstein, 1983 & Audiology \\
\hline Malnutrition* & White et al., 2012 & Nutrition \\
\hline $\begin{array}{l}\text { Oral Health Screening / } \\
\text { Denture Evaluation }\end{array}$ & Safety Net Medical Home, n.d. & Dental Medicine \\
\hline Orthostatic Blood Pressure* & Centers for Disease Control, 2017 & Geriatric Medicine \\
\hline Pain Interference & Weiner et al., 2016 & Geriatric Medicine \\
\hline SMART Goals* & Doran, 1981 & $\begin{array}{l}\text { Speech Language } \\
\text { Pathology }\end{array}$ \\
\hline Social Isolation & $\begin{array}{l}\text { Gottlieb \& Bergen, 2010; } \\
\text { Maguire, } 1991\end{array}$ & Social Work \\
\hline Vision Impairment & & Ophthalmology \\
\hline
\end{tabular}

\section{Evaluation Design \& Instruments}

This course evaluation was deemed exempt per institutional IRB policy since it examined the effectiveness of and compared instructional techniques and curricula and was designed to evaluate the program not the students. To examine interprofessional skill and competency, students completed a pre- and post-course Interprofessional Collaborative Competency Attainment Survey- Revised (ICCAS-R; Schmitz et al., 2017). The ICCAS- 
$\mathrm{R}$ is a 21-item scale designed for retrospective pre-post learner self-assessment of interprofessional competency attainment and is a modified and separately validated version of the ICCAS scale developed by McDonald et al. (2010). The first 20 items use a 5-point Likert response scale $(1=$ poor to $5=$ excellent $)$ to measure self-rated ability to perform each item. The last item is a transition item to assess self-rated ability to collaborate interprofessionally compared to the time before the course $(1=$ worse now to $5=$ much better now). Responses to this item moderately correlate with pre-post changes in responses to individual items and support learner global insight into impact of an educational intervention (Schmitz et al., 2017). To enhance priming effect on interprofessional learning objectives, we administered the pre-portion of the ICCAS-R prior to the course. We administered the post-portion, along with the transitional item, at course completion. Due to the Dunning-Kruger effect (Kruger \& Dunning, 1999), whereby novices tend to overestimate their abilities, and become more accurate with increasing competence, administering the test in this manner may overestimate pre-course ability and, therefore, underestimate overall change in self-rated ability for individual items. For this reason, we used the transition item, which correlates with pre-post change in self-rating on individual ICCAS-R items, as a second measure of self-rated change in ability.

Individual ICCAS-R items map onto both the Canadian Interprofessional Health Collaborative Interprofessional Competency Framework (2010) and the Interprofessional Education Collaborative (IPEC, 2016) Core Competencies for Interprofessional Collaborative Practice. The items can be grouped into subscales for (1) interprofessional communication, (2) interprofessional collaboration, (3) roles and responsibilities, (4) collaboration with patients and families, (5) conflict management and resolution, and (6) team functioning. The scale has been validated by Archibald et al. (2014), Schmitz et al. (2017), and Violato and King (2019) with interprofessional students. In addition to the ICCAS-R, at post-test, we asked students to indicate which of the learning activities "provided the most authentic (interprofessional) collaborative experience." Demographic data were also collected.

\section{Data Analyses}

Student names were never placed on the surveys to protect privacy; each student was given a unique identifier, and only one administrative staff person had access to information connecting that identifier to a name. That person was not course faculty and did not participate in data analysis. Personnel with training in statistical and data analysis who did not have any direct interaction with students or access to student names completed the data analysis.

Descriptive statistics on age, race, gender, disadvantaged background, and response rate were analyzed. Descriptive statistics were generated on ICCAS-R items by profession. Because the number of students in the separate health professions outside medicine was small, paired t-tests compared pre and post ratings of competence on ICCAS-R items for two groups of students: health profession students (HPs) and HP medical students. Medical students in non-IP groups were excluded as their learning experience was fundamentally different than students in IP groups. 


\section{Results}

A total of 209 students participated in the 2018 IP geriatrics course with the following professional distribution: 131 medical, 4 dental, 15 nursing, 17 nutrition, 8 occupational therapy, 20 pharmacy, 4 physician assistant, 9 social work, and 1 speech language pathology. Physical therapy students typically enroll in the course; there were no participants in 2018 due to schedule restrictions. Physical therapy faculty members remained involved as facilitators.

One hundred sixty-two students $(77 \%)$ answered a portion of the demographic questions. Please See Table 3 for details. Thirty-two of the 38 people who disclosed they were males were medical students. Thirteen percent $(n=21)$ of the students indicated that they considered themselves as having come from a disadvantaged background, defined as coming from an environment with barriers to attaining skills or accessing education for training as a health professional or from a family with low income; 13\% (n=21) did not respond or disclose this information.

\begin{tabular}{lr} 
Table 3. Descriptive Information about Students \\
\cline { 2 - 2 } & \multicolumn{1}{c}{$\mathrm{n}(\%)$} \\
\hline Age & \\
20-29 years & $120(74.1 \%)$ \\
30-39 years & $19(11.7 \%)$ \\
Did not respond/disclose & $23(14.2 \%)$ \\
\hline Gender & \\
Female & $77(47.5 \%)$ \\
Male & $38(23.5 \%)$ \\
Did not respond/disclose & $47(29.0 \%)$ \\
\hline Race / Ethnicity & \\
African American & $11(6.8 \%)$ \\
Asian & $18(11.1 \%)$ \\
Caucasian & $105(64.8 \%)$ \\
Latinx & $4(2.5 \%)$ \\
Mixed & $3(1.9 \%)$ \\
Did not respond/disclose & $25(15.4 \%)$ \\
\hline Location “Grew Up” & \\
Suburban & $94(58.0 \%)$ \\
Rural & $31(19.1 \%)$ \\
Urban & $15(9.3 \%)$ \\
Did not respond/disclose & $22(13.6 \%)$ \\
\hline
\end{tabular}

As presented in Table 4, descriptive statistics and paired t-tests of pre and post ICCAS$\mathrm{R}$ responses examined change in self-rated competency for HPs $(\mathrm{n}=58)$ and medical students on IP teams $(\mathrm{n}=78)$. Analysis of the surveys using t-tests $(p<0.05)$ for each of the six ICCAS-R subscales indicated that both medical students and HPs rated their interprofessional competency greater after completing the week's activities. HPs rated themselves as having improved skills on all 20 items with statistical significance at $<0.05$. 
An item-by-item analysis of each ICCAS-R item using t-tests resulted in only two items out of the 20 where the mean self-rating of medical students was not significantly higher: (1) including the patient/family in decision-making, $t(78)=0.830, p=.205$; and (2) taking into account the ideas of other IP team members $t(78)=1.524, p=.066)$.

Table 4. Pre-Post Self-rated IP Competence (ICCAS-R Subscale Comparison)

\begin{tabular}{|c|c|c|c|c|c|c|c|c|}
\hline \multirow[b]{2}{*}{ ICCAS-R Subscale } & \multicolumn{4}{|c|}{ HP* Medical Students } & \multicolumn{4}{|c|}{ HP Students } \\
\hline & $\begin{array}{l}\text { Mean } \\
\text { Change }\end{array}$ & SD & $t(78)$ & $p$ & $\begin{array}{c}\text { Mean } \\
\text { Change }\end{array}$ & SD & $t(58)$ & $p$ \\
\hline IP communication & 0.39 & 0.67 & 5.17 & $<.001$ & 0.45 & 0.73 & 4.38 & $<.001$ \\
\hline IP collaboration, & 0.34 & 0.84 & 3.57 & $<.001$ & 0.47 & 0.80 & 4.18 & $<.001$ \\
\hline Roles \& responsibilities & 0.25 & 0.70 & 3.18 & 0.001 & 0.56 & 0.73 & 5.54 & $<.001$ \\
\hline $\begin{array}{l}\text { Collaboration with } \\
\text { patients \& families }\end{array}$ & 0.33 & 0.74 & 3.93 & $<.001$ & 0.60 & 0.63 & 5.54 & $<.001$ \\
\hline $\begin{array}{l}\text { Conflict management \& } \\
\text { resolution }\end{array}$ & 0.21 & 0.78 & 2.36 & 0.011 & 0.40 & 0.66 & 4.33 & $<.001$ \\
\hline Team functioning & 0.28 & 0.79 & 3.14 & 0.001 & 0.68 & 0.86 & 5.63 & $<.001$ \\
\hline
\end{tabular}

Descriptive statistics were generated for each ICCAS-R item if the profession had five or more student responses. Post-test mean scores represented higher self-rating in IP skills after the week's activities for each profession except for two items for one profession. DNPs reported the only drop in mean (3.92 to 3.73) on a single item, rating themselves lower for actively listening to IP team members' ideas after the experience. Nutrition students indicated no change (mean 3.57) in their ability to work effectively with IP team members to enhance care after the experience.

For a more global impression of students self-rated skills, we used the ICCAS-R single transition item "Compared to the time before this course, would you say your ability to collaborate interprofessionally is: worse now, somewhat worse now, about the same, somewhat better now, or much better now." Sixty-nine percent of students $(62 \%$ medical, 94\% pharmacy, $75 \%$ DNP, $100 \%$ SW, $83 \%$ OT, 62\% nutrition) rated themselves as somewhat or much better able to collaborate interprofessionally after the course. No students rated themselves as worse or somewhat worse.

Students were asked to identify which of the learning activities "provided the most authentic collaborative experience" (see Table 5). A competitive team-based learning game entitled "Hospital Survivor" was rated as the most authentic skill-building interprofessional activity by $33 \%(\mathrm{n}=45)$ of the students. This was followed by the "health assessment fairs" $(n=24,18 \%)$ and "most of the activities" $(n=23,17 \%)$. The health assessment fairs were a service-learning activity where students used skills learned during the geriatric assessment skills fair [Table 2] to screen older adults nine 9 senior communities for various health needs and provide them with information to take to their primary care provider. Further breakdown by professions with 5 or more responses indicated that the medical $(n=23$, $29 \%)$, pharmacy $(\mathrm{n}=11,61 \%), \mathrm{DNP}(\mathrm{n}=3,38 \%)$, and nutrition $(\mathrm{n}=6,38 \%)$ students selected "Hospital Survivor" as the most authentic. SW (n=2, 40\%) indicated that most of the activities were authentic, and the health assessment fairs $(n=2,40 \%)$ as the most authentic. 
Only a small group of medical students indicated that they found none of the experiences as authentic $(\mathrm{n}=11,14 \%)$.

Table 5. Health Profession Students' Most Authentic IP Learning Experiences

\begin{tabular}{|c|c|c|c|c|c|}
\hline \multirow[b]{2}{*}{ Activity } & \multicolumn{5}{|c|}{$\mathrm{n}(\%)$} \\
\hline & $\begin{array}{c}\text { Medical } \\
(n=79)\end{array}$ & $\begin{array}{l}\text { DNP } \\
(n=8)\end{array}$ & $\begin{array}{c}\text { Nutrition } \\
(\mathrm{n}=16)\end{array}$ & $\begin{array}{c}\text { Pharmacy } \\
(n=18)\end{array}$ & $\begin{array}{c}\mathrm{SW} \\
(\mathrm{n}=5)\end{array}$ \\
\hline Team-building ice breaker & $3(4 \%)$ & $1(13 \%)$ & & & $1(20 \%)$ \\
\hline Is it worth it & $10(13 \%)$ & $1(13 \%)$ & $1(6 \%)$ & $2(11 \%)$ & \\
\hline Hospital horror & $10(13 \%)$ & $1(13 \%)$ & $2(13 \%)$ & & \\
\hline Hospital survivor & $23(29 \%)$ & $3(38 \%)$ & $6(38 \%)$ & $11(61 \%)$ & \\
\hline Health assessment fairs & $13(16 \%)$ & $1(13 \%)$ & $4(25 \%)$ & $2(11 \%)$ & $2(40 \%)$ \\
\hline Most of the experiences & $9(11 \%)$ & $1(13 \%)$ & $3(19 \%)$ & $3(17 \%)$ & $2(40 \%)$ \\
\hline None of the experiences & $11(14 \%)$ & & & & \\
\hline
\end{tabular}

\section{Discussion}

Evaluation of this IP geriatrics course suggests that students, overall, rated themselves as more competent to practice interprofessionally after participating in IP team-based learning activities related to geriatrics - a finding consistent with faculty hypotheses prior to the training and student reports from previous years of this program. This was true when the data were analyzed along the ICCAS-R subscales and when analyzed item-by-item, except for two items for medical students: including patients/families in decision-making and taking into account the ideas of other IP team members. For those items, the medical students still rated themselves as improved, but these changes were not significant. It should be noted that medical students reported significant improvement in the ICCAS-R competency subscales (Interprofessional Communication and Collaboration with Patients and Families) in which these two individual items were grouped, suggesting that the lack of significant improvement on these two specific items did not negatively impact overall perceived improvement in competence.

The amount of pre-test to post-test change appears to be slightly greater for the remaining health professions students than for the medical students. Violato and King (2019) suggest that effect sizes using the ICCAS are likely to be greater in students without interprofessional experience than those who have interprofessional experience during their training prior to using the tool. Our study seems to reveal the opposite. Based on our knowledge of students' curricula related to interprofessional and clinical experiences, our medical students seem to have had less IP experience than students in the other health professions. Even so, they report significant gains in perceived interprofessional competence that were only slightly less than the students who seem to have more IP experience. Sixty-two percent of medical students reported that they perceived themselves as somewhat or much better able to collaborate after the course, the same percentage as students from nutrition.

Medical students' and health professions students' comments to an open-ended question about the week suggest that each group started the week with a different 
understanding of interprofessional practice and may have gained something different from it. The results may reflect these differences in the student groups. The HP students from the schools of nursing, pharmacy, rehabilitation sciences, dentistry, and social work volunteered to participate in the program; they rearranged busy academic schedules to complete the week's activities, suggesting high motivation and interest in IP practice. Most, like social workers (with generalist field placement) or DNPs (with past work experience), already had IP clinical experience before the course, which may have primed them for how to use the week to grow their IP skills. As one social work student commented, "The biggest take away for me was that I have an important contribution to make to the team, especially around psychosocial factors and community, plus I feel more confident in my ability to contribute to the team."

On the other hand, the interprofessional geriatrics course is required for medical students to graduate. The course takes place near the midpoint of third year in between clerkship (clinical) experiences. Many medical students indicate reticence to be pulled back into the classroom from clinical, direct patient care experiences which seem more important, authentic, and relevant to their training. As a result, some medical students report starting the course with lower expectations for its value and lower motivation to build IP skills. These contextual realities may exert some influence over medical students' attitudes and explain the somewhat smaller effect sizes for change in the medical students' self-rating.

Faculty decisions about which of the health profession students to invite as participants may also have contributed to the difference in the two groups of students. Baseline skills and knowledge were considerations, in addition to IP experience, when faculty selected students. In social work, for example, faculty made the decision that students should be familiar with medical terminology and settings or gerontological or health care social work based on expectations for the learning activities. Faculty thought this would make the learning activities more meaningful and enable them to participate more fully. This led to only inviting students pursuing integrated health or gerontology certificates who had completed their generalist course work (typically done in the first year of social work training).

In discussion with course faculty after the experience, integrated health students (i.e., social work students learning how to integrate behavioral health intervention into health care settings) anecdotally reported gaining more new knowledge about geriatrics; gerontology students stated that they added more knowledge depth and nuance in some areas. Even though more advanced social work students were selected, they reported struggling to participate in the geriatric pharmacology case activity and Is It Worth It debate. They also reflected verbally that they might not have been prepared to participate at the beginning of their training as they did not yet know the social work role in health care. As social work continues to participate, faculty will need to elicit further feedback to determine which students can benefit the most and whether students earlier in their social work education or in other specializations, such as mental health, might benefit. Faculty in the other professions must also continue to evaluate student selection criteria, and the course planning team will need to continue to modify the activities to be inclusive of any new professional students that join. 
The strengths of this study include the design of the educational intervention used to teach IP teamwork competency, the deliberate balanced interprofessional team structure, the use of a validated, reliable and widely used tool to measure change in interprofessional competency, and the IP teamwork of its faculty to design the course and interpret the evaluation results. The design of the curriculum-using real-life case exemplars that students would face in multiple experiential formats and service-learning activities that moved students outside the classroom-was deliberate and meant to address the apprehension the medical students expressed about classroom-based learning. One-third of students rated a gamified, case-based, team simulation exercise entitled "Hospital Survivor" (see Table 1) as the most authentic interprofessional learning experience. This was followed by the health assessment fairs (16\% of students), a service-learning activity. Inclusion of such activities is not only supported by HPAC (2019), it is consistent with educational theory about creating scaffolding that reinforces the process of transferring learning from training settings to real-world settings (Roumell, 2019). We cannot determine based upon our evaluation if it was the gamification features that contributed to the high rating of "Hospital Survivor."

We believe the team composition, attempting to have only about half of the students from medicine with 3 to 5 professions per team, resulted in students' valuing interprofessional teams and the improvement in IP competency. This is consistent with Lairamore et al.'s (2018) work that suggests smaller IPE team composition and not having every profession represented produces a greater recognition by learners that they need 1) exposure to the expertise and contributions of multiple health care disciplines in patient care and 2) teamwork to comprehensively address the challenges of complex patients. Additionally, the team composition also seemed to address perceived stereotypes or expectations that physicians would be the leaders in patient care, particularly in acute care. For example, during the Is It Worth It exercise, teams realized that the physician is not always the best person to lead on specific patient needs and features, sometimes choosing one of the other professionals to lead. While there has been little attention to power perceptions in IP learning, Wharton and Burg (2017) suggest, that training like this can lead to the more egalitarian, shared leadership philosophy of the high-functioning IP team.

One strength of using the ICCAS-R is that it covers most, if not all, domains or characteristics of high-functioning teams. Administration of the ICCAS-R at the outset of the course may have served to "prime" students' learning by introducing them to core concepts, characteristics, and competencies associated with high-functioning teams. This evaluation cannot determine if it did that, in part, because the faculty also communicated these concepts with the opening ice-breaker exercise and as they explained the week's activities, encouraging students to try to form their own high-functioning teams. The authors, who are also course planning committee members, wove bits of expertise from every discipline into each IP activity to emphasize the interdependent nature of highfunctioning teams.

\section{Limitations}

We acknowledge several limitations. Medical students were required to attend while health professions students volunteered. Students also came with a range of real-life 
clinical and interprofessional team experiences that we did not measure in advance. The medical students, for whom the course was initially created and required, may have had less clinical and interprofessional experience to inform their IP behavior and performance in this course; social work and nurse practitioner students may have had more. This may make the comparisons less valid. Further complicating the interprofessional team dynamic is the traditional hierarchical culture of medicine where the physician has often been the default leader charged with decision-making authority. This traditional culture, which is shifting slowly, probably continues to exert some influence on students' understanding of patient care and health-care decision-making, despite changes in both educational and clinical settings.

Using an instrument that relies on the student's self-reported competence may also be a limitation. Self-report, especially among high achievers, can skew to overly confident subjective estimates of ability. Furthermore, the authors wonder about the students' level of familiarity with the competencies and the sophisticated IP terminology used on the questionnaire they were completing. Perhaps the newness of or unfamiliarity with these IP concepts at the beginning of the week attenuated the confidence bias students might have otherwise exhibited. These points suggest we may wish to use the ICCAS-R retrospectively rather than as a tool to prime students. In analyzing the results and running the high number of tests, we are unable to rule out type I error (rejecting the null hypothesis when the null is actually true).

We also acknowledge the short period that we gave students to learn and practice interprofessional competencies and the fact that they did so outside the realm, reality, and high- stakes of actual patient care. Transfer of learning into clinical practice will take more than four 8- hour days and five IP team experiences to achieve mastery in interprofessional team competencies. Still, this experience is an excellent foundation on which to build future clinical IPE experiences. Clearly there is less urgency to achieving mastery in a low-stakes, simulated learning environment. Simulation is intended to facilitate learning and practice of high-stakes skills in low-risk environments, in preparation for real-world settings, giving students a chance to make mistakes and grow without harming patients. Simulated, casebased learning can help students understand each discipline's role and expertise and realize that no single profession can deliver high quality patient care without collaborating with professionals from different disciplines. Future evaluation of the course could examine if the IP learning in this short-term experience transfers into greater competence once the experience is over.

\section{Conclusion}

We developed a highly experiential five-day geriatrics course with an integrated interprofessional education curriculum for health professions students from 10 disciplines who worked in 23 interprofessional teams to complete multiple patient care simulations. The simulations were carefully created to emphasize the contributions and expertise of every discipline and to force team members to rely on each other's expertise to provide optimal patient care. The results of a pre-test/post-test survey on interprofessional team competencies showed that all students made significant gains in all 6 subscale domains. Students from social work, nurse practitioner, pharmacy, and rehabilitation sciences (OT, 
SLP, nutrition) seemed to have more clinical and interprofessional health care team experience at the time of the course and reported a slightly greater degree of improvement in their IP competency levels than third year medical students. Medical students, the majority of the students, also significantly improved in all subscale domains of IP competence.

Based on this evaluation, faculty will increase the authenticity of future simulations by mimicking and presenting them with real-world clinical challenges, increase the role of technology and gamification to create a more high-stakes feel for the work students do, and improve efforts to hardwire multidisciplinary interdependence into the simulations. Faculty will also continue to enhance the relevance of all activities for every discipline, particularly as some disciplines, such as social work and nutrition, are newly involved in the experience. Future evaluation will try to tease out the influence of gamification and consider ideas for how to evaluate patient outcomes after the experience is over.

\section{References}

Ashman, J. J., Rui, P., \& Okeyode, T. (2019). Characteristics of office-based physician visits, 2016. NCHS Data Brief, 331. Atlanta, GA: Centers for Disease Control. https://www.cdc.gov/nchs/data/databriefs/db331-h.pdf

Archibald, D., Trumpower, D., \& MacDonald, C. J. (2014). Validation of the interprofessional collaborative competency attainment survey (ICCAS). Journal of Interprofessional Care, 28(6), 553-558. https://doi.org/10.3109/13561820.2014.917407

Baker, D. P., Day, R., \& Salas, E. (2006). Teamwork as an essential component of highreliability organizations. Health Services Research, 41(4), 1576-1598. https://doi.org/10.1111/j.1475-6773.2006.00566.x

Baker, D. P., Gustafson, S., Beaubien, J., Salas, E., \& Barach, P. (2005). Training teams: Medical teamwork and patient safety: The evidence-based relation. Agency for Healthcare Research and Quality. https://archive.ahrq.gov/research/findings/finalreports/medteam/medteamwork.pdf

Barker J. (2007). Error reduction through team leadership: What surgeons can learn from the airline industry. Clinical Neurosurgery, 54, 195-199.

Biehle, L., \& Jeffres, M. (2018). Play games and score points with students. The Clinical Teacher, 15(6), 445-450. https://doi.org/10.1111/tct.12763

Borson, S., Scanlan, J. M., Watanabe, J., Tu, S. P., Lessig, M. (2005). Simplifying detection of cognitive impairment: Comparison of the Mini-Cog and Mini-Mental State Examination in a multiethnic sample. Journal of the American Geriatrics Society, 53(5), 871-874. https://doi.org/10.1111/j.1532-5415.2005.53269.x

Brandt, B., Lutfiyya, M. N., King, J. A., \& Chioreso, C. (2014). A scoping review of interprofessional collaborative practice and education using the lens of the Triple Aim. Journal of Interprofessional Care, 28(5), 393-399. https://doi.org/10.3109/13561820.2014.906391 
Canadian Interprofessional Health Collaborative. (2010, February). A national interprofessional competency framework. Vancouver, BC: Author. http://ipcontherun.ca/wp-content/uploads/2014/06/National-Framework.pdf

Centers for Disease Control. (2017). Assessment: Measuring orthostatic blood pressure. https://www.cdc.gov/steadi/pdf/STEADI-Assessment-MeasuringBP-508.pdf

Cerra, F. B., \& Brandt, B. F. (2015). The growing integration of health professions education. In S. Wartman (Ed.), The transformation of academic health centers: Meeting the challenges of healthcare's changing landscape (pp. 81-90). Elsevier. https://doi.org/10.1016/B978-0-12-800762-4.00009-8

Chakraborti, C., Boonyasai, R. T., Wright, S. M., \& Kern, D. E. (2008). A systematic review of teamwork training interventions in medical student and resident education. Journal of General Internal Medicine, 23(6), 846-853. https://doi.org/10.1007/s11606-008-0600-6

Collamati, A., Martone, A. M., Poscia, A. Brandi, V., Celi, M., Marzetti, E., Cherubini, A., \& Landi, F. (2016). Anticholinergic drugs and negative outcomes in the older population: from biological plausibility to clinical evidence. Aging Clinical and Experimental Research, 8(1), 25-35. https://doi.org/10.1007/s40520-015-0359-7

Coupland, C. A. C., Hill, T., Denning, T, Moriss, R., Moore, M., \& Hippisley-Cox, J. (2019). Anticholinergic drug exposure and the risk of dementia: A nested casecontrol study. JAMA: Internal Medicine, 179(8), 1084-1093. https://doi.org/10.1001/jamainternmed.2019.0677

Covinsky, K. E., Pierluissi, E., \& Johnston, C. B. (2011). Hospitalization-associated disability "She was probably able to ambulate, but I'm not sure." JAMA, 306(16), 1782-1793. https://doi.org/10.1001/jama.2011.1556

Doran, G. T. (1981). There's a S.M.A.R.T. way to write management's goals and objectives. Management Review, 11, 35-36. https://community.mis.temple.edu/mis0855002fall2015/files/2015/10/S.M.A.R.TWay-Management-Review.pdf

Felton, M., Tannenbaum, C., McPherson, M. L., \& Pruskowski, J. (2019). Communication techniques for deprescribing conversations \#369. Journal of Palliative Medicine, 22(3), 335-336. https://doi.org/10.1089/jpm.2018.0669

Fried, L. P., Bandeen-Roche, K., Williamson, J. D., Prasada-Rao, P., Chee, E., Tepper, S., \& Rubin, G. S. (1996). Functional decline in older adults: Expanding methods of ascertainment. The Journals of Gerontology: Series A, 51A(5), M206-M214. https://doi.org/10.1093/gerona/51a.5.m206

Gottlieb, B. H., \& Bergen, A. E. (2010). Social support concepts and measures. Journal of Psychosomatic Research, 69, 511-520. https://doi.org/10.1016/j.jpsychores.2009.10.001

Greiner, A. C., \& Knebel, E. (Eds.). (2003). Health professions education: A bridge to quality. National Academies Press. https://www.ncbi.nlm.nih.gov/pubmed/25057657 
Gentry, S. V., Gauthier, A., Ehrstrom, B., L., Wortley, D., Lilienthal, A., Car, L. T., Dauwels-Okutsu, S., Nikolaou, C. K., Zary, N., Campbell, J., \& Car, J. (2019). Serious gaming and gamification education in health professions: A systematic review. Journal of Medical Intern Research, 21(3), e12994. https://doi.org/10.2196/12994

Guraya, S. Y., \& Barr, H. (2018). The effectiveness of interprofessional education in healthcare: A systematic review and meta-analysis. Kaohsiung Journal of Medical Sciences, 34(3), 160-165. https://doi.org/10.1016/j.kjms.2017.12.009

Hall, P., \& Weaver, L. (2001). Interdisciplinary education and teamwork: A long and winding road. Medical Education, 35, 867-875. https://doi.org/10.1046/j.13652923.2001.00919.x

Health Professions Accreditors Collaborative [HPAC]. (2019). Guidance on developing quality interprofessional education for the health professions. Chicago, IL: Author. https://healthprofessionsaccreditors.org/wpcontent/uploads/2019/02/HPACGuidance02-01-19.pdf

Health Resources Services Administration. (n.d.). Geriatrics. Retrieved from https://bhw.hrsa.gov/grants/geriatrics

Holmes, H. M., Hayley, D. C., Alexander, G. C., \& Sachs, G. A. (2006). Reconsidering medication appropriateness for patients late in life. Archives of Internal Medicine, 166(6), 605-609. https://doi.org/10.1001/archinte.166.6.605

Inouye, S. K., Bogardus, S. T., Charpentier, P. A., Leo-Summers, L., Acampora, D., Holford, T. R., \& Cooney, L. M. (1999). A multicomponent intervention to prevent delirium in hospitalized older patients. New England Journal of Medicine, 340(9), 669-676. https://doi.org/10.1056/nejm199903043400901

Institute of Medicine [IOM]. (2008). Retooling for an aging America: Building the health care workforce. The National Academies Press. Retrieved from https://www.ncbi.nlm.nih.gov/books/NBK215401/

IOM. (2015). Measuring the impact of interprofessional education on collaborative practice and patient outcomes. The National Academies Press. Retrieved from https://www.nap.edu/read/21726/chapter/1

Interprofessional Education Collaborative. (2016). Core competencies for interprofessional collaborative practice: 2016 update. Author. Retrieved from https://hsc.unm.edu/ipe/resources/ipec-2016-core-competencies.pdf

Interprofessional Education Collaborative Expert Panel. (2011). Core competencies for interprofessional collaborative practice: Report of an expert panel. Author. https://www.uthsc.edu/simulation/documents/ipec-report.pdf

Isaacs/Jellinek. (2019, January). Assessment of the accomplishments and impact of the John A. Hartford Foundation's grantmaking in aging and health, 1983-2015. New York, NY: The John A. Hartford Foundation. Retrieved from https://www.johnahartford.org/images/uploads/reports/JAHF_Accomplishments_Imp 
act_Report_FINAL_1.7.2019.pdf

Kempen, F., Yardley, L, van Haastregt, J., Zijlstra, G., Beyer, N., Hauer, K., \& Todd, C. (2008). The short FES-I: A shortened version of the Falls Efficacy Scaleinternational to assess fear of falling. Age and Ageing, 37(1), 45-50. https://doi.org/10.1093/ageing/afm157

Kloss, B. (2019, August 25). Anticholinergic toxidrome. Life in the FastLane. https://litfl.com/anticholinergic-toxidrome/

Kohn, L. T., Corrigan, J. M., \& Donaldson, M. S. (Eds.) (2000). To err is human: Building a safer health system. Committee on Quality of Health Care in America, Institute of Medicine. National Academies Press. Retrieved from https://www.ncbi.nlm.nih.gov/books/NBK225182/

Kroenke, K., Spitzer, R. L., \& Williams, J. B. W. (2001). The PHQ-9: Validity of a brief depression severity measure. Journal of General Internal Medicine, 16(9), 606-613. https://doi.org/10.1046/j.1525-1497.2001.016009606.x Kruger, J., \& Dunning, D. (1999). Unskilled and unaware of it: How difficulties in recognizing one's own incompetence lead to inflated self-assessments. Journal of Personality and Social Psychology, 77(6), 1121-1134. https://doi.org/10.1037/0022-3514.77.6.1121

Kua, C., Mak, V. S. L., \& Lee, S. W. H. (2019). Health outcomes of deprescribing interventions among older residents in nursing homes: A systematic review and metaanalysis. Journal of Post-Acute and Long-Term Care Medicine, 20(3), 362-372. https://doi.org/10.1016/j.jamda.2018.10.026

Lairamore, C., Morris, D., Schichtl, R., George-Paschal, L., Martens, H., Maragakis, A., Garnica, M., Jones, B., Grantham, M., \& Bruenger, A. (2018). Impact of team composition on student perceptions of interprofessional teamwork: A 6-year cohort study. Journal of Interprofessional Care, 32(2), 143-150. https://doi.org/10.1080/13561820.2017.1366895

MacDonald, C. J., Archibald, D., Trumpower, D. L., Casimiro, L., Cragg, B., \& Jelley, W. (2010). Designing and operationalizing a toolkit of bilingual interprofessional education assessment instruments. Journal of Research in Interprofessional Practice and Education, 1(3), 304-316. https://doi.org/10.22230/jripe.2010v1n3a36

Maguire, L. (1991). Social Support systems in practice: A generalist approach. NASW Press.

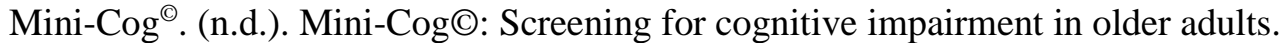
https://mini-cog.com/

Morley J. E., Vellas, B., van Kan G. A., Anker, S. D., Bauer, J. M., Bernabei, R., Cesari, M., Chumlea, W. C., Doehner, W., Evans, J., Fried, L. P., Guralnik, J. M., Katz, P. R., Malmstrom, T. K., McCarter, R. J., Gutierrez Robledo, L. M., Rockwood, K., von Haehling, S., Vandewoude, M. F., \& Walston, J. (2013). Frailty consensus: A call to action. Journal of the American Medical Directors Association, 14(6), 392-397. https://doi.org/10.1016/j.jamda.2013.03.022 
National Center for Health Statistics. (2017). Health, United States. In Health, United States, 2016: With chartbook on long-term trends in health. https://www.cdc.gov/nchs/data/hus/hus16.pdf

Pruskowski, J., Sakely, H., \& Handler, S. (2019). Development of a required longitudinal residency experience focused on deprescribing. American Journal of Health-System Pharmacy, 76(4), 236-241. https://doi.org/10.1093/ajhp/zxy029

Quach, L., Galica, A. M., Jones, R. N., Procter-Gray, E., Manor, B., Hannan, M. T., \& Lipsitz, L. A. (2011). The non-linear relationship between gait speed and falls: The MOBILIZE Boston Study. Journal of the American Geriatrics Society, 59(6), 10691073. https://doi.org/10.1111/j.1532-5415.2011.03408.x

Reeves, S., Palagana, J., \& Zierler, B. (2015). Appendix B: Synthesis of interprofessional education reviews. In Institute of Medicine (Ed.), Measuring the impact of interprofessional education on collaborative practice and patient outcomes, (pp. 135145). The National Academies Press. https://doi.org/10.17226/21726

Rockwood, K., Song, X., MacKnight, C., Berman, H., Hogan, D. B., McDowell, I., \& Mitnitski, A. (2005). A global clinical measure of fitness and frailty in elderly people. Canadian Medical Association Journal, 173(5), 489-495. https://doi.org/10.1503/cmaj.050051

Roumell, E. A. (2019). Priming adult learners for learning transfer: Beyond content and delivery. Adult Learning, 30(1), 15-22. https://doi.org/10.1177/1045159518791281

Safety Net Medical Home. (n.d.). Oral health: An essential component of primary care. http://www.safetynetmedicalhome.org/sites/default/files/Oral-Health-ScreeningQuestions.pdf

Salas, E., DiazGranados D, Klein, C., Burke, C. S., Stagl, K. C., Goodwin, G. F., \& Halpin, S. M. (2008). Does team training improve team performance? A metaanalysis. Human Factors. 50(6), 903-933. https://doi.org/10.1518/001872008x375009

Salas, E., Weaver, S. J., DiazGranados, D., Lyons, R., \& King, H. (2009). Sounding the call for team training in health care: some insights and warnings. Academic Medicine, 84(10), S128-S131. https://doi.org/10.1097/acm.0b013e3181b37d48

Schmitz, C. C., Radosevich, D. M, Jardine, P., MacDonald, C. J., Trumpower, D., \& Archibald, D. (2017). The interprofessional collaborative competency attainment survey (ICCAS): A replication validation study. Journal of Interprofessional Care, 31(1), 28-34. https://doi.org/10.1080/13561820.2016.1233096

Scott, I. A., Hilmer, S. N., Reeve, E., Potter, K., Le Couteur, D., Rigby, D., Gnjidic, D., Del Mar, C. B., Roughead, E. E., Page, A., Jansen, J., \& Martin, J. H. (2015). Reducing inappropriate polypharmacy: The process of deprescribing. JAMA Internal Medicine, 175(5), 827-834. https://doi.org/10.1001/jamainternmed.2015.0324 
Shear, M. K., Simon, N., Wall, M., Zisook, S., Neimeyer, R., Duan, N., Reynolds, C., Lebowitz, B., Sung, S., Ghesquiere, A., Gorscak, B., Clayton, P., Ito, M., Nakajima, S., Konishi, T., Melhem, N., Meert, K., Schiff, M., O’Connor, M., ... Keshaviah, A. (2011). Complicated grief and related bereavement issues for DSM-5. Depression \& Anxiety, 28(2), 103-117. https://doi.org/10.1002/da.20780

Sheikh, J. I., \& Yesavage, J. A. (1986). Geriatric depression scale (GDS): Recent evidence and development of a shorter version. Clinical Gerontologist, 5(1-2), 165173. https://doi.org/10.1300/j018v05n01 09

Spitzer, R. L., Kroenke, K., Williams, J. B. W., \& Lowe, B. (2006). A brief measure for assessing generalized anxiety disorder: The GAD-7. Archives of Internal Medicine, 166(10), 1092-1097. https://doi.org/10.1001/archinte.166.10.1092

U.S. Centers for Disease Control and Prevention. (2010). Number, percent distribution, rate, days of care with average length of stay, and standard error of discharges from short-stay hospitals, by sex and age: United States, 2010. Atlanta, GA: Author. https://www.cdc.gov/nchs/data/nhds/2average/2010ave2_ratesexage.pdf

Weinstein, B. E., \& Ventry, I. (1983). Audiologic correlates of hearing handicap in the elderly. Journal of Speech, Language, and Hearing Research, 26(1), 148-151. https://doi.org/10.1044/jshr.2601.148 Vespa, J., Armstrong, D. M., \& Medina, L. (2018, March). Demographic turning points for the United States: Population projections for 2020 to 2060. Suitland, MD: U.S. Census Bureau. https://permanent.access.gpo.gov/gpo93743/P25_1144.pdf

Violato, E. M., \& King, S. (2019). A validity study of interprofessional collaborative competency attainment survey: An interprofessional collaborative competency measure. Journal of Nursing Education, 58(8), 454-462.

https://doi.org/10.3928/01484834-20190719-04

Thompson, W., Reeve, R., Moriarty, F., Maclure, M., Turner, J., Steinman, M. A., Conklin, J., Dolovich, L. McCarthy, L., \& Farrell, B. (2019). Deprescribing: Future directions for research. Research in Social and Administrative Pharmacy, 15(6), 801805. https://doi.org/10.1016/j.sapharm.2018.08.013

Weiner, D. K., Marcum, Z., \& Rodriguez, E. (2016). Deconstructing chronic low back pain in older adults: Summary recommendations. Pain Medicine, 17(12), 2238-2246. https://doi.org/10.1093/pm/pnw267

Wharton, T., \& Burg, M. A. (2017). A mixed-methods evaluation of social work learning outcomes in interprofessional training with medicine and pharmacy students. Journal of Social Work Education, 53(sup1), S87-S96.

https://doi.org/10.1080/10437797.2017.1288592

White, J. V., Guenter, P., Jensen, G., Malone, A., \& Schofield, M. (2012). Consensus statement: Academy of Nutrition and Dietetics and American Society for Parenteral and Enteral Nutrition. Journal of Parenteral and Enteral Nutrition, 36(3), 275-283. https://doi.org/10.1177/0148607112440285 
World Health Organization. (2010). Framework for action on interprofessional education \& collaborative practice. Author.

https://apps.who.int/iris/bitstream/handle/10665/70185/WHO_HRH_HPN_10.3_eng. pdf?sequence $=1$

Author note: Address correspondence to Elizabeth Mulvaney, School of Social Work, University of Pittsburgh, 2117 Cathedral of Learning, Pittsburgh, PA 15260. Email: eam65@ pitt.edu

Acknowledgement: We are grateful for the leadership, administrative and financial support needed to implement this course provided by the University of Pittsburgh Office of Medical Education, the School of Medicine, John Mahoney, MD (Associate Dean of the Office of Medical Education), and the Division of Geriatric Medicine. We are also grateful for the support and volunteer faculty provided by the University of Pittsburgh's Schools of Pharmacy, Nursing, Social Work, and Health and Rehabilitation Sciences. 